\title{
Erratum: Defining digital medicine
}

Eric Elenko, Lindsay Underwood \& Daphne Zohar

Nat. Biotechnol. 33, 456-461 (2015); published online 12 May 2015; corrected after print 13 October 2016.

In the version of this article initially published, PureTech was incorrectly credited for the illustration on p. 457. The Biosensing Body Image illustration is by Abby B. Marsh. The error has been corrected in the HTML and PDF versions of the article. 